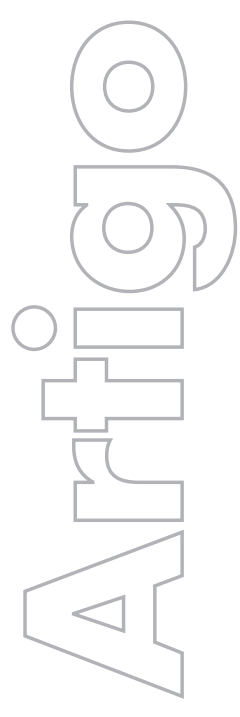

revista

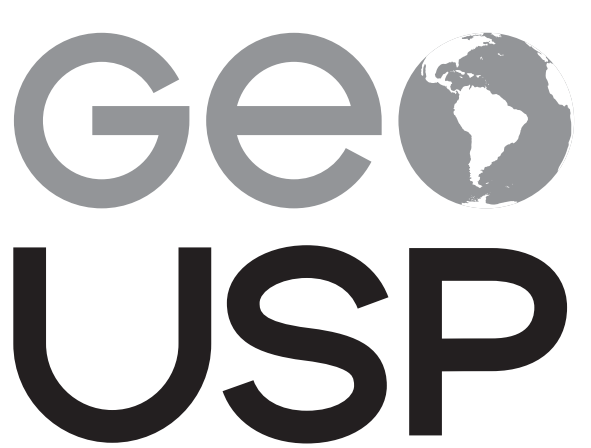

espaço e tempo

Volume $23 \cdot n^{\circ} 1$ (2019)

ISSN 2179-0892

\section{A expansão da securitização imobiliária: uma prospecção a partir da cidade de Ribeirão Preto-SP}

\author{
Everaldo Santos Melazzo \\ Unesp \\ e-mail: melazzo@fct.unesp.br \\ Marlon Altavini de Abreu \\ Unesp \\ e-mail: marlon.altavini@gmail.com
}

p. 022-039

Como citar este artigo:

MELAZZO, E. S.; ABREU, M. A. A expansão da securitização imobiliária: uma prospecção a partir da cidade de Ribeirão Preto-SP. Geousp - Espaço e Tempo (Online), v. 23, n. 1, p. 022-039, abr. 2019. ISSN 2179-0892.

Disponível em: https://www.revistas.usp.br/geousp/article/ view/141943. doi: https://doi.org/10.11606/issn.2179-0892. geousp.2019.141943.

\section{(C) $(1) \circledast$}

Este artigo está licenciado sob a Creative Commons Attribution 4.0 License. 


\section{A expansão da securitização imobiliária: uma prospecção a partir da cidade de Ribeirão Preto-SP}

\section{Resumo}

Este artigo analisa a disseminação de mecanismos de securitização de ativos de base imobiliária, contextualizando-a no crescente processo de transformação da terra, da habitação e da cidade em ativos financeiros que, a partir da antecipação de rendas futuras (principalmente fundiárias), alimenta circuitos por onde circulam e se valorizam diferentes capitais. $\bigcirc$ termo disseminação é aqui tratado em três vertentes: a primeira, ao se debruçar sobre o caso da cidade de Ribeirão Preto-SP, amplia o debate para a identificação dos processos analisados em cidades médias e não exclusivamente em realidades metropolitanas como parte da literatura nacional e internacional insiste em focar; a segunda, ao constatar que tais processos, antes restritos a vetores seletivos de valorização imobiliária na cidade, tem se disseminado espacialmente em direção a diferentes áreas e bairros da cidade, capturando para sua lógica aqueles que anteriormente eram considerados como de baixas liquidez e inserção no mercado imobiliário e, a terceira, ao constatar a presença cada mais significativa de imóveis residenciais no conjunto dos bens imobiliários securitizados. Além de reforçar a conviç̧ão sobre um paulatino e crescente processo de transformação cada vez mais intenso da terra e da habitação em ativos de valor, distancia-os cada vez mais do significado de direito à cidade que seu acesso pode significar.

Palavras-chave: Securitização. Ativos imobiliários. Dinâmica Imobiliária. Cidades Médias. Ribeirão Preto-SP.

\section{The expansion of real estate securitization: a prospection from the city of Ribeirão Preto-SP}

\footnotetext{
Abstract

The article investigates the dissemination of mechanisms for securitization of real estate assets, contextualizing it in the growing process of transformation of land, housing and the city into financial assets in order to anticipate future incomes (mainly on urban land) feeding circuits where different capitals circulate. The term dissemination is dealt with in three aspects: the first, when examining
} 
the case of the city of Ribeirão Preto/SP, expands the debate to identify the processes analyzed in médium-size cities and not exclusively in metropolitan realities, in spite of the national and international literature insists on focusing; The second is that these processes, previously restricted to selective vectors of real estate apreciation in the city, now extend spatially, capturing for their logic areas and neighborhoods previously considered as low liquidity and insertion in the real estate market, and the third, verifying the increasing presence of residential real estate in the whole of the securitized real estate. In addition to reinforcing the conviction about a gradual and growing process of increasingly intense transformation of land and housing into assets of value, the increasing distance of the meaning of right to the city that their access can mean.

Keywords: Securitization. Real Estate Dynamics. Median-size Cities. Ribeirão Preto-SP.

\section{La expansión de la securitización inmobiliaria: una prospección a partir de la ciudad de Ribeirão Negro-SP}

\section{Resumen}

Este artículo, en el campo de los estudios inmobiliarios-habitacionales, investiga la diseminación de mecanismos de securitización de activos de base inmobiliaria, ubicándolo en el creciente proceso de transformación de la tierra, de la vivienda y de la ciudad en activos financieros que, a partir de la anticipación de rentas futuras (principalmente las originadas del suelo urbano) alimentan circuitos donde circulan diferentes capitales. El término diseminación es aquí tratado en tres vertientes: la primera, al examinar el caso de la ciudad de Ribeirão Preto / SP, amplía el debate para la identificación de los procesos analizados en ciudades medias y no exclusivamente en realidades metropolitanas, como parte de la literatura nacional e internacional insiste en enfocar; la segunda, al constatar que tales procesos, antes restringidos a vectores selectivos de valorización inmobiliaria en la ciudad, hoy se extienden espacialmente, capturando para su lógica áreas y barrios tomados anteriormente como de baja liquidez e inserción en el mercado inmobiliario y, la tercera, al constatar la presencia cada más significativa de inmuebles residenciales en el conjunto de los bienes securitizados. Además de reforzar la convicción sobre un paulatino y creciente proceso de transformación cada vez más intensa de la tierra y de la vivienda en activos de valor, los distancia cada vez más del significado de derecho a la ciudad que su acceso puede significar.

Palabras clave: Securitización. Activos inmobiliarios. Dinámica Inmobiliaria. Ciudades Intermedias. Ribeirão Preto-SP. 


\section{Introdução}

As inovações de produtos e processos são aceleradas no âmbito do sistema financeiro, mas o mesmo não pode ser afirmado em relação à velocidade necessária a sua compreensão aprofundada. Dentre tais inovações, ainda em processo, a estruturação de um mercado baseado em títulos financeiros com lastro em bens imobiliários ou de base imobiliária, tem povoado o temário de pesquisas a respeito da financeirização da economia e suas conexões com as dinâmicas urbanas recentes, mesmo que ainda muito precise se analisado.

$\bigcirc$ debate a ser desenvolvido neste artigo se refere à criação, desenvolvimento e expansão dos instrumentos de securitização imobiliária na realidade brasileira que expressa, em particular, as condições que atrelam cada vez mais a propriedade imobiliária e fundiária ao mercado de capitais, conformando o que vários autores, sob perspectivas distintas, têm denominado como financeirização do imobiliário ou da política habitacional e seus desdobramentos sobre as cidades (Botelho, 2007; Royer, 2009; Sanfelici, 2013; Pereira, 2015; Rolnik, 2015; Melazzo, 2016).

No Brasil, a criação do Sistema Financeiro Imobiliário (SFI) na década de 1990 (Lei n. 9.514/1997) e a emergência paulatina de um aparato regulatório que lhe confere conteúdo, operacionalidade e segurança jurídica, inaugura importantes mudanças não apenas para novos instrumentos e possibilidades relacionados diretamente ao financiamento imobiliário. Trata-se, sobretudo, de uma reconfiguração jurídica da propriedade imobiliária, que diz respeito à construção de conexões entre a esfera financeira e o ambiente construído urbano.

Reconhecendo que esta é uma primeira aproximação aos desafios mais amplos para a compreensão destes processos é mister reconhecer também que este artigo não pretende abordá-los integralmente. Porém, a já significativa produção acadêmica sobre a articulação entre as esferas de valorização do capital financeiro e a produção e o consumo da cidade e da habitação, mesmo que ainda bastante fragmentada, parecem dar pouca importância, ainda, a três dimensões que serão valorizadas no presente artigo. De um lado, tal literatura em geral volta suas atenções aos espaços metropolitanos, deixando de lado uma lógica que já se faz presente, de maneira seletiva, em todo o território capturando cidades de diferentes portes e em diferentes níveis da hierarquia urbana às lógicas financeiras. De outro, ao restringir a análise às escalas globais, nacionais e metropolitanas deixa de lado a escala da cidade como crucial para a compreensão dos elos que unem as dinâmicas das rendas fundiárias e imobiliárias às financeiras. Por fim, deve ser considerada também a expansão de tais mecanismos sobre os imóveis de uso residencial/habitacional e não apenas aqueles de usos eminentemente econômicos, como os industriais, comerciais e de serviços.

Tendo em vista tais questões, o objetivo principal deste artigo é analisar, a partir de uma cidade média específica, Ribeirão Preto, no Estado de São Paulo, o processo de disseminação da produção desses ativos imobiliários para porções cada vez mais amplas do espaço urbano, a partir do crescente mercado da securitização imobiliária no Brasil. A escala da cidade é aqui privilegiada para a identificação de quais mercadorias/ativos se trata e onde se localizam como duas dimensões cruciais para a compreensão da lógica geral que preside tal processo. 
Além desta Introdução, o artigo é organizado em mais quatro itens. No segundo, são discutidas de uma maneira mais detalhada algumas definições de securitização, os produtos que gera (os títulos securitizados) e os principais agentes envolvidos em suas diferentes etapas que conformam a produção e o consumo destes papéis no Brasil. Desta discussão, procura-se extrair os determinantes mais gerais e algumas inferências teóricas que dão suporte à sua compreensão. $\bigcirc$ terceiro item destina-se, brevemente, a apresentar de maneira sistematizada a fonte e os dados utilizados uma vez que são poucos ou mesmo inexistentes ainda os trabalhos que se debruçam sobre o complexo conjunto de informações dos denominados "pacotes de emissão" diretamente compilados das fontes primárias que os produzem, os agentes securitizadores. Espera-se contribuir para a disseminação e o aprimoramento do tratamento empírico deste imenso conjunto de dados. No item seguinte, o quarto, o artigo se volta à realidade concreta da cidade de Ribeirão Preto/SP. Através da análise de dois conjuntos de emissões de títulos securitizados, comandadas por dois agentes securitizadores específicos, será possível observar alterações significativas na lógica econômica e espacial do processo, permitindo a problematização do que poderiam ser denominados efeitos espaciais de expansão desta lógica securitizadora. Nas Considerações finais, além de uma síntese argumentativa em que a empiria analisada possa ser melhor interpretada, são retomados caminhos de análise que demandam ainda aprofundamento analítico para uma correta avaliação sobre a captura da cidades na lógica financeira.

\section{A securitização: processos, agentes e lógicas}

Securitização é a denominação genérica para uma prática do mundo das finanças que consiste em transformar certos tipos de mercadorias em papéis. As mercadorias em questão e os rendimentos que potencialmente possam gerar passam a se constituir como lastro ou base dos papéis emitidos e a remuneração destes últimos fica assegurada pelo fluxo de rendimentos (ou fluxo de caixa) que a mercadoria gera durante um certo período de tempo futuro.

Neste sentido, a mercadoria em questão converte-se em um ativo que possibilita a remuneração de títulos, através da criação de uma cuidadosa engenharia de intermediação financeira em que emerge uma particular divisão do trabalho: os detentores dos direitos do fluxo de rendimentos gerados real ou potencialmente pelos ativos, que os vendem a partir de uma certa taxa de desconto (taxa de juros); as companhias securitizadoras que cuidam de reunir as diferentes mercadorias para que, formando um conjunto/pacote de ativos potencializem seus rendimentos e emitam os papéis correspondentes ao conjunto com as garantias de rendimentos que passam a ter como expectativa; os agentes de avaliação que analisam e atestam a qualidade e potencialidade de geração de remuneração dos papeis e seus compradores finais, que os adquirem em função também de expectativas de rentabilidade para seus investimentos.

Se de um lado tal caracterização é ainda geral, permite por outro lado constatar que se trata de processo que reúne diferentes agentes, mas que se encontram comandados por uma ação específica de transformar as expectativas dos rendimentos futuros de uma mercadoria em 
base de remuneração para investimentos financeiros no presente. Naquilo que mais diretamente interessa ao debate deste artigo, que são os bens imobiliários, trata-se de reconhecer, no plano do imediato, o processo de transformar um bem imóvel, com suas características intrínsecas, em um direito de rendas futuras incorporado a títulos de valor negociados nos mercados financeiros.

Porém, as mediações para que tal processo seja possível, e dissemine-se, demanda investigações no plano teórico e histórico. Sobre este último, faz-se necessário conhecer as trajetórias que condicionam o surgimento deste tipo de intermediação financeira a partir dos anos de 1970 nos Estados Unidos da América, seu alastramento e dimensão diferenciada para cada país, em função dos distintos "níveis de amadurecimento" de seus mercados financeiros vis a vis ao conjunto de normas e instituições públicas e privadas que the dão suporte e que mudam ao longo do tempo, bem como o aparecimento e o papel que passa a desempenhar cada agente deste circuito e seu poder de impor taxas, prazos e ritmos para sua disseminação (Fix, 2011; Sanfelici, 2015).

Se faz necessário, assim, conhecer concretamente quem, e como se estruturam tais agentes, colocando em marcha um mercado de securitização lastreado em bens imobiliários distintos, bem como onde se localizam e quais são estes imóveis que passam a circular em um novo mercado, o de títulos securitizados.

Do ponto de vista teórico os desafios são também grandes na exata medida em que a vinculação entre uma lógica de produzir rendas futuras através de papéis que circulam em seu mercado específico com os imóveis, sua produção e seu consumo e, em última instância a própria produção das cidades não são triviais (Harvey, 1990; Haila, 1988, 1990).

Impõem-se, assim, reconstruir as determinações gerais que permitam explicitar que para alguns agentes econômicos emerge um novo valor de uso para os bens imobiliários que é única e exclusivamente o de gerar rendas futuras que satisfaçam seus cálculos econômicos. Tal lógica encontra um nicho específico e propício na própria produção da mercadoria terra e imóveis, mercadorias que já portam em si um potencial de dar suporte a rendas, e suas alterações não apenas em relação à localização em um espaço absoluto, mas fundamentalmente relativo e relacional produzidos pelo capitalismo em seu permanente e contraditório processo de transformação expansiva (Harvey, 1990).

A criação de instrumentos financeiros de base imobiliária capazes de possibilitar a captação de recursos no mercado secundário de títulos de crédito e recebíveis imobiliários aparece como a principal condicionante desta estrutura de financiamento imobiliário que, ao regulamentar os chamados fundos de investimento imobiliário (FII), introduz as operações de securitização imobiliária no Brasil. Como braço operacional necessário à sua realização, surgem as companhias securitizadoras, responsáveis pela emissão dos certificados de recebíveis imobiliários (CRI).

$\bigcirc$ impulso modernizador, que comparece como justificativa de sua implantação, pretendido em relação a períodos do passado, em que as fontes de financiamento habitacional estavam desenhadas a partir do Fundo de Garantia por Tempo de Serviço (FGTS) e pelo Sistema Brasileiro de Poupança em Empréstimo (SBPE), via Sistema Financeiro Habitacional (SFH), seria justamente a criação de novas fontes para tais financiamentos (Royer, 2009, 2016). 
Os "velhos" instrumentos de mobilização e captação de recursos já teriam esgotado seu potencial, em detrimento dos "novos", que promoveriam a ampliação, agora via mercado, dos canais e das possibilidades de captação de financiamento imobiliário.

A construção desta nova engenharia financeira revela, entretanto, que para além da promessa realizada de fundos capazes de alimentar a produção imobiliária de maneira permanente, entrega-se um novo padrão de articulações entre o imobiliário e financeiro inédito no caso brasileiro, mas já conhecidos em suas variedade em outros países tal como analisado por Fix (2011), Sanfelici (2013, 2017) e Royer (2016).

O novo marco regulatório da propriedade e do financiamento imobiliário no Brasil passam a estar submetidos ao processo mais geral que, já no subtítulo de sua obra, Rolnik (2015) denomina "colonização da terra e da moradia pelas finanças".

A introdução das operações de securitização, como lembra a mesma autora, apresenta uma maior complexidade associada à estruturação e desenvolvimento de um mercado de capitais, preparado para operações complexas, assim como um mercado imobiliário voltado e preparado para operar com esse mercado de capitais. Emergem desses vínculos entre produção imobiliária, incluindo-se aqui também com o solo urbano, e capital financeiro tal como defendido por Pereira (2015), duas dimensões fundamentais à modelagem de um sistema de financiamento baseado num ambiente institucional capaz de promover segurança e garantias à captação e acesso de recursos via mercado de capitais para a produção, em última instância, da habitação.

A primeira, assentada na segurança jurídica dos credores, em outras palavras, na instituição de mecanismos que confiram garantias de retorno de investimentos frente aos tomadores de crédito. A instituição da Alienação Fiduciária (Lei n. 9.514/1997) e do Patrimônio de Afetação (Lei n. 10.931/2014) respondem a esta demanda, comparecendo como mecanismos jurídicos introduzidos para aquela finalidade.

A Alienação Fiduciária, por um lado, permitiu maior facilidade na execução da garantia real em casos de inadimplência, visto que a propriedade do imóvel só se realiza com a quitação do saldo devedor. Configura-se em uma importante inovação no campo jurídico capaz de se contrapor à lenta execução feita com hipotecas (Royer, 2009), visto que no sistema hipotecário o imóvel poderia ter sua posse e domínio transferido ao mutuário mesmo com pagamento parcial do imóvel entre 20\% e 30\% do saldo devedor. Os fundamentos desta medida conectam o beneficiário ao crédito e não mais ao imóvel.

Patrimônio de Afetação, por outro lado, estabeleceu condições para a proteção de credores, direcionados às operações de financiamento à produção imobiliária. De maneira geral, consiste em um mecanismo que promove a separação dos ativos vinculados a uma determinada incorporação imobiliária do conjunto de bens que integram o patrimônio de um incorporador (Pereira, 2015; Royer, 2009).

Almeja-se com estes mecanismos o destravamento da propriedade e da casa, tornando-a potencialmente mobilizável e segura para negociação, conferindo maior solidez ao ambiente regulatório orientado para o mercado (Rolnik, 2015), favorecendo a criação de títulos e instrumentos de captação e intermediação de recursos no âmbito do mercado financeiro. 
Esses novos produtos das finanças, os CRI, ampliam a liquidez do ativo imobiliário por meio da divisibilidade do investimento em títulos acessíveis tanto a pequenos investidores individuais, quanto a grandes conglomerados financeiros (Shimbo, 2012) e são complementados a partir da Lei n. 10.931/2004, com a criação das cédulas de crédito imobiliário (CCI), as letras de crédito imobiliário (LCI) e as letras imobiliárias garantidas (LIG).

A disseminação destes títulos lastreados em direitos creditícios originados em operações de financiamento imobiliário arregimenta formas contratuais de concessão do crédito imobiliário, padronizando-as sob um conjunto de normas e regulamentações que conferem condições de efetivamente disciplinar e mobilizar todo objeto imobiliário potencialmente mobilizável, alinhando-o às formas de circulação internacional da riqueza. Ademais, indica os nexos que atuam para a aproximação progressiva e cada vez mais incisiva do ambiente construído urbano e o mercado de capitais.

Esta lógica financeirizada de ação passa a ser internalizada nas estruturas do setor imobiliário, sincronizando o funcionamento de instâncias de intermediação e realização das expectativas e rendimentos cujo lastro conecta uma base imobiliária e seus rendimentos como dívidas de financiamento ou promessas de aluguéis ou, simplesmente, fluxos de caixa projetados para o futuro, passíveis de serem calculados antecipadamente a uma taxa de desconto.

Os CRI, objeto de nossa análise, são instrumentos projetados para essa finalidade última, revelando um encadeamento institucional complexo de financiamento, captura e conversão da dívida imobiliária em formas de ganhos esperados, portanto sujeitas a cada vez mais à instabilidade das incertezas e que potencializam ganham especulativos.

Visto desta maneira, a emissão dos CRI constituem uma cadeia de obrigações jurídicas e garantias contratuais extensa, que articula um conjunto amplo de agentes, em diferentes etapas com objetivo de alavancar recursos para novos financiamentos. A invenção de uma sofisticada divisão do trabalho emerge e sua estrutura subentende a conversão de uma dívida, originada pela aquisição ou construção de um imóvel, em direitos sobre os recebíveis a uma companhia securitizadora.

Estas, por sua vez, reúnem diferentes créditos e emitem títulos que possuem como lastro os recebíveis provenientes de um empreendimento imobiliário (Royer, 2009). Tais emissões, como veremos a seguir, possuem diferentes formatações, podendo estar associadas a um único empreendimento ou podem reunir diferentes títulos de dívida originadas de diferentes imóveis, constituindo um fluxo de pagamentos da carteira de créditos organizada.

Reunido num pacote, antes de seguir para a oferta no mercado, esse conjunto de recebíveis passa por ajustes nos termos da securitização, segregado que é do regime fiduciário, e é posteriormente conduzido à Comissão de Valores Mobiliários (CVM) para aprovação.

Esse circuito se completa com a comercialização no mercado de capitais. Esta função é normalmente atribuída às corretoras de valores mobiliários. Nesta etapa, os CRI recebem notas associadas aos riscos do pacote em avaliações realizadas por agencias de avaliação, agente que cumpre o papel de conferir notas hierarquizadas da segurança e qualidade de tais papeis sobre a solidez de sua capacidade de gerar os fluxos de rendas esperados.

Considerando a evolução recente das emissões de CRI no Brasil, observadas a partir do Gráfico 1, é possível constatar a franca evolução do número de emissões e dos valores totais emitidos. 


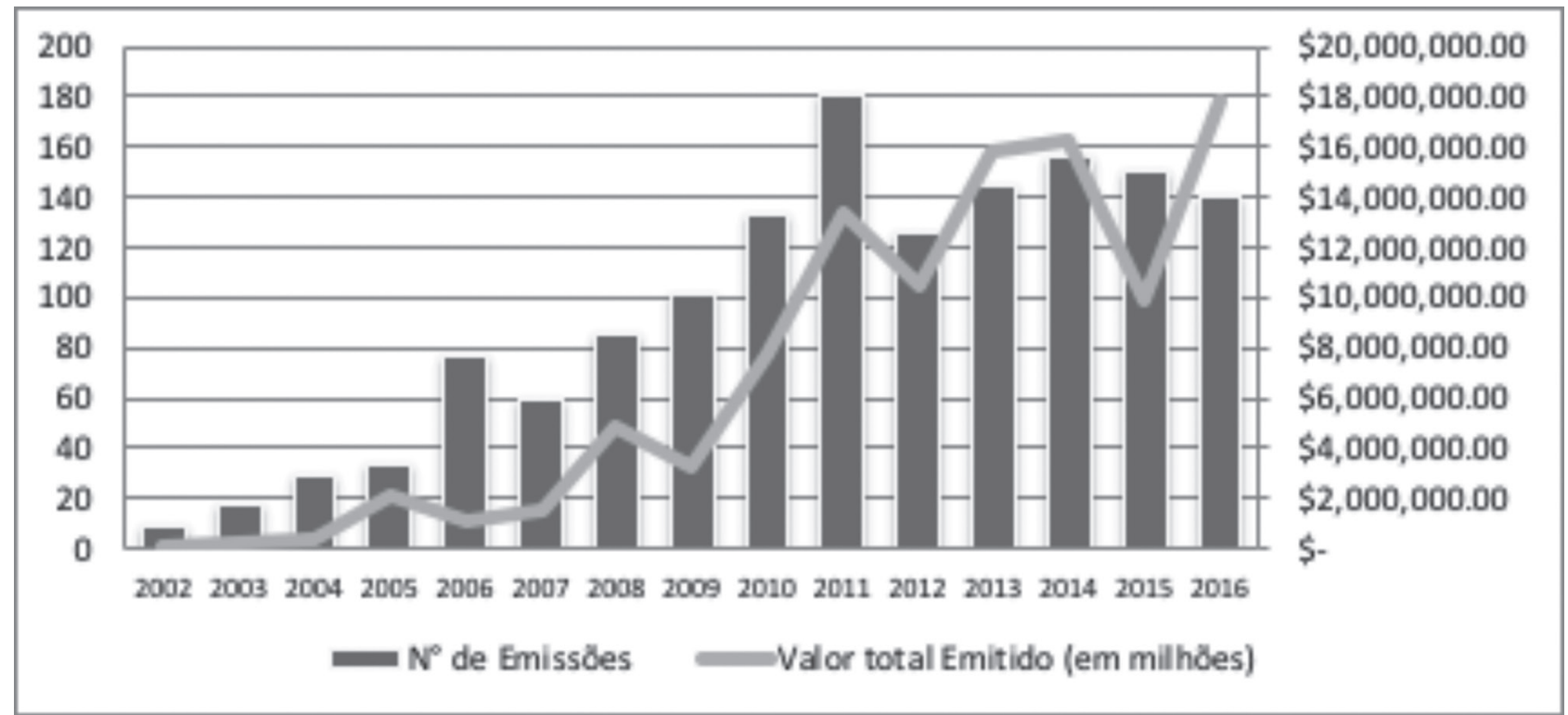

fonte: Anbima ([s.d.]) e Comissão de Valores Mobiliários ([s.d.]). organização: Os autores.

Considerando a evolução recente destas emissões é possível constatar a franca evolução do número de emissões e dos valores totais emitidos. No período indicado pelo Gráfico 1 verifica-se uma elevação do número de emissões que em 2002 totalizaram nove, chegando a 181 em 2011 e fechando 2016 com 140 emissões. Ademais, a evolução dos valores emitidos anualmente segue a mesma tendência de aumento, alcançando mais de R \$ 17 bilhões em 2016.

Esses números crescentes indicam claramente a marcada e progressiva inclusão desses títulos na composição de diferentes fundos de investimento - como o fundo de investimento em direitos creditórios (FDIC) e o fundo de investimentos imobiliários (FII) - e sua estreita conexão com estratégias de investimento a partir do financiamento de empreendimentos comerciais e complexos de edifícios voltados aos segmentos de alta renda e espacialmente circunscritos a regiões metropolitanas (Royer, 2016; Sanfelici, 2017).

Porém, sobretudo a partir do ano de 2010, é possível verificar alterações substanciais na composição deste mercado, evidenciando mudanças no que tange aos tipos de imóveis que passam a compor o pacote de emissões, dando lastro às emissões de CRI. Mais ainda, observa-se o papel crescente de novos agentes participantes deste mercado, sobretudo o Conselho Curador do FGTS, que passa a atuar na sua estruturação e expansão.

Retomando o Gráfico 1, podem ser observados dois momentos distintos na relação entre o número de emissões e valores totais emitidos: o primeiro refere-se aos anos de 2002 a 2009 e o segundo entre os anos de 2010 a 2016. A mudança no crescimento do patamar dos dois indicadores correspondem às transformações dos arranjos regulatórios e do modo como este mercado vem desenvolvendo formas de ampliar a inserção de novos agentes que sejam capazes de oferecer maior liquidez a estes títulos de modo a assegurar os rendimentos desejados por seus operadores.

Esta versão local de ativos securitizados, por mais que inspirado nos mortgage backed securities estadunidenses, tal como abordado por Fix (2011), não foram capazes de constituir condições semelhantes aos empréstimos do tipo subprime que aproximassem esta estrutura de financiamento às camadas de mais baixa renda da população (Fix, 2011). 
Em sua evolução, como é possível observar sobretudo no primeiro momento (2002 a 2009), persiste a indicação do que pode ser designado como uma aproximação truncada entre capital financeiro e setor imobiliário no Brasil, seguindo as indicações de Fix (2011), momento este cujos empreendimentos, ferramentas de captação financeira, fundos de investimento e agentes promotores integram-se a um circuito de produção restrito e profundamente enraizados a um tipo específico de mercadoria, voltado a edifícios comerciais, praças empresarias, hotéis de luxo e empreendimentos habitacionais destinados aos segmentos de mais alta renda.

Essa é uma característica também destacada por Rolnik (2015), que ressalta a dificuldade de se consolidar um mercado secundário no Brasil dado a pouca capacidade de mobilização de recursos e ampliação do circuito imobiliário por meio dos CRI e de FII, restritos aos tipos de empreendimento já destacados aqui.

Atentos a essas questões, também Sanfelici (2013) e Pereira (2015), a partir de entrevistas com agentes financeiros, sobretudo, representantes de empresas securitizadoras, captam o discurso que associa a compreensão desses limites. Ou seja, a maior inserção desses títulos a rendimentos associados majoritariamente à exploração de imóveis comerciais seria um constrangimento imposto pela própria estrutura do sistema de financiamento habitacional no Brasil, em função de suas fontes e recursos creditícios captados a baixo custo, atrelando-se ainda às regras de exigibilidade a que estão submetidas as entidades de poupança e empréstimo. A imposição aos bancos de aplicarem $65 \%$ dos depósitos nas cadernetas de poupança em financiamento habitacional restringiria a ampliação deste mercado, visto que a possibilidade de desenquadramento a que estariam submetidos estas agencias ao transferir os direitos creditícios para as empresas de securitização, incentivaria a manutenção de uma carteira de ativos imobiliários.

É possível compreender como a evolução e consolidação dos mercados de títulos imobiliários fazem parte de um campo de disputa pelo acesso às fontes e recursos do SFH pelo SFI, identificando sempre o primeiro como um sistema limitado e atrasado, tal como explicitado por Royer (2009).

Assim, quando retomado o Gráfico 1 é importante associar a tendência verificada de expansão do mercado para os CRI a esse embate. A elevação dos indicadores, sobretudo após o ano de 2010 indica uma dinâmica permanente de ajustes institucionais sobre estes títulos. Essas sucessivas transformações do aparato regulatório aliadas à expansão do crédito ao setor imobiliário, circunstanciam o aumento das emissões em relação aos anos anteriores e nos volumes comercializados de CRI observados.

Analisando a evolução desses indicadores entre os anos de 2006 e 2012, Royer (2016) destacará a importância da expansão desses mercados frente à elevação dos estoques de recursos que passam a integrar de modo mais sistemático os ativos de FII e FIDC,' além de sua disseminação pelas vendas desses títulos no segmento de varejo dos bancos e redução dos valores para a aplicação nestes títulos. Contudo, chama mais a atenção neste período o ganho gradual de importância das emissões de CRI com lastro em imóveis de uso residencial, deslocando paulatinamente o interesse dos agentes securitizadores para as emissões de títulos lastreados em financiamentos imobiliários residenciais .

1 Como lembra a autora, apesar de haver sido criados em 1993, esses fundos só foram a regulamentados em 2008, por meio da Companhia de Valores Mobiliários (CVM) n. 472, ampliando o mercado de diversos títulos financeiros, entre eles, os CRI. 
A autora atribuirá às mudanças regulatórias no direcionamento da poupança e o ganho crescente de importância do FGTS na alavancagem das emissões de CRI, ampliando o desempenho esperado para seus operadores (Royer, 2016), reconfigurando o perfil dos negócios para estes ativos que notavelmente chegam no ano de 2011 apresentando a maioria das operações com lastro em créditos/financiamentos para a aquisição imobiliária em detrimento das locações.

Por exemplo, 2011 se destaca dos demais anos analisados, e o relatório anual da Uqbar $(2012)^{2}$ explicita uma importante inflexão nas normas que regulamentam o uso dos recursos do FGTS para aquisição de CRI, com mudanças no direcionamento de recursos captados em depósitos de poupança pelas diferentes entidades que compõem o SBPE. ${ }^{3}$

São removidos os entraves impostos pelas regras de exigibilidade estabelecidos às entidades de poupança e empréstimos, que obrigavam os bancos a aplicarem alta porcentagem das captações do Sistema de Poupança e Empréstimos (SBPE), ${ }^{4}$ transformando-as em exigibilidades de CRI, na medida em que estes passam a cumprir as condições de destinação de recursos à habitação de interesse social, tornando os grandes bancos seus principais investidores. ${ }^{5}$

Naquele ano, em particular, os recursos do FGTS foram utilizados para a compra de cerca de 20\% dos CRIs emitidos (Uqbar, 2012), conferindo a liquidez mínima a estes títulos e estabelecendo a comunicação definitiva entre os diferentes sistemas de financiamento imobiliário (SFH e SFI). Deste modo, a captura do fundo público com a finalidade de conferir maior liquidez a estes títulos passam a configurar um elemento central e ao mesmo tempo contraditório de alavancagem do mercado de títulos lastreados em imóveis, cada vez mais de uso residencial.

A posição do FGTS entre os principais investidores em CRI será mantida nos anos subsequentes: ocupa em 2012 a condição de principal investidor, adquirindo cerca de 37,4\% dos CRI emitidos; em 2013 adquire 14\% dos CRI emitidos; em 2014 participa da compra de 23\% dos CRI emitidos; com 9\% no ano de 2015 e, no ano de 2016 assume a posição de principal investidor, adquirindo $53 \%$ dos CRI emitidos. ${ }^{6}$

$\bigcirc$ ano de 2011, marca ainda um ponto de inflexão nestas operações na medida em que o lastro em crédito imobiliário foi, neste ano, superior aos lastros com base em locação, situação semelhante ao ano de 2015 (Uqbar, 2017).

As mudanças na estrutura regulatória e a entrada de um novo agente com participação crescente no mercado, como foi o caso do FGTS, implicou assim não apenas em aumentos substanciais das emissões e dos valores, mas também mudanças nos tipos de produtos imobiliários utilizados como lastros e, possivelmente nas escalas de interação destes títulos frente à dinâmica urbana de diversas cidades brasileiras.

2 Empresa criada em 2003, especializada em assessoria e consultoria em securitização imobiliária e privete equity (Uqbar, [s.d.]).

3 Ademais, nesse ano, vigorou o preço mínimo de investimentos, ampliando a circulação desses títulos no varejo (Royer, 2016).

4 Resolução do Banco Central n. 3.259, de 2005.

5 A Resolução n. 4.410, de 2015, restringe a equivalência desses títulos frente à exigibilidade, extinguindo, pela Resolução n. 3.932 do Banco Central do Brasil, a possibilidade de que investimentos em CRI com lastro fora do formato do SFH fossem enquadrados para fins da exigibilidade regular.

6 Informações extraídas dos relatórios Uqbar (2012, 2013, 2014, 2015, 2016). 


\section{Sobre os dados empíricos e suas fontes}

A compilação e sistematização de dados dos CRI buscaram caracterizar os agentes envolvidos na negociação, o tipo de produto vinculado ao crédito imobiliário e as características gerais dos imóveis lastreados, como o valor financiado e sua localização na cidade.

Essas informações foram compiladas a partir das séries históricas de emissões dos CRI de duas empresas, a Companhia Brasileira de Securitização e a Brazilian Securities, cuja escolha responde a sua importância no volume de emissões de CRI, concentrando pouco mais de 47\% do mercado de securitização no Brasil (Uqbar, 2017). Assim, dado o foco deste artigo, foram registradas todas as menções à cidade de Ribeirão Preto entre as primeira emissões no ano de 2002 até 2016.

Assim, de cada um dos documentos consultados, foram extraídas informações sobre a cidade de Ribeirão Preto, identificando o agente emissor (companhias de securitização), o agente cedente e o coordenador líder. Essas informações permitem compreender a origem do crédito imobiliário que compõe a emissão analisada. Em outras palavras, se esse crédito está associado a uma construtora ou a um agente financeiro (bancos e companhias hipotecárias), revelando algumas especificidades da estrutura e dos agentes do mercado imobiliário da cidade estudada.

Ademais, outras informações compiladas destes documentos permitem caracterizar os recebíveis que expressam as promessas de ganhos, isto é, identificar se as dividas que compõem estas emissões estão relacionadas a alugueis ou financiamentos para aquisição, ou ainda se estes empréstimos foram tomados nas empresas construtoras ou em agencias bancárias que concederam financiamentos e companhias hipotecarias.

Por fim, informação crucial para os argumentos aqui desenvolvidos, foram compiladas as informações que nos permitam localizar os imóveis que servem de lastro às emissões. Para tanto, foram extraídas as informações referentes ao endereço, constando rua, número e bairro destes imóveis, assim como a identificação destes empreendimentos: se são multi ou unifamiliares (prédios de apartamentos ou residências unifamiliares) e seus usos, residenciais, comerciais, de serviços etc.

\section{A securitização em Ribeirão Preto}

Identificando as emissões de CRI contendo em sua composição imóveis localizados na cidade Ribeirão Preto (Quadro 1), realizadas pela securitizadora Cibrasec ${ }^{7}$ é possível enumerar algumas características associadas aos pacotes emitidos, destacando os agentes envolvidos na negociação, o tipo de produto vinculado ao crédito imobiliário e as características gerais dos imóveis lastreados.

Importante ressaltar que estes pacotes de emissões consultados, em sua maioria, caracterizam-se por emissões pulverizadas, ou seja, seu lastro está composto por uma gama diversa de empreendimentos dispersos em várias cidades em diferentes regiões do país. Nestas emissões, mesclam-se empreendimentos vinculados a imóveis pertencentes a pessoas físicas e a empresas, à compra de unidades habitacionais e à grandes áreas de terrenos urbanos.

As informações sobre a cidade de Ribeirão Preto sintetiza em grande medida este conjunto de informações, pormenorizando as que dizem respeito ao número de registro e data das emissões analisadas. Além disso, evidencia os agentes cedentes e o coordenador

7 As emissões analisadas e mapeadas correspondem às séries 52 do ano de 2006, às séries 105, 106, 107, 108, 109, 110, 111, 112 e 113, de 2009, e à série 187, de 2012. 
líder dos pacotes, a quantidades de CRI que compõe a oferta e o total registrado para a cidade de Ribeirão Preto e, por fim, a predominância dos usos dos empreendimentos utilizados como lastro no pacote.

No que tange aos agentes relacionados ao crédito e aos imóveis vinculados verificamos a existência de formas variadas de captação de recursos. A série 52 do ano de 2006 faz referência a um único empreendimento residencial, cedido pela empresa construtora, sob regime hipotecário. Nesse empreendimento, a empresa construtora cede à empresa securitizadora os direitos aos seus rendimentos futuros. Este modelo, contudo, não se repetirá nas emissões subsequentes.

As séries do ano de 2009 encontram-se divididas em duas emissões, reunindo créditos emitidos pelo banco Bradesco. Esses créditos referem-se em sua maioria a empreendimentos residenciais e à compra de duas grandes áreas por uma empresa incorporadora local. ${ }^{8}$ A série do ano de 2012 é a única de cunho comercial, cuja promessa de pagamento está associada ao aluguel de um galpão produzido pela empresa cedente à empresa proprietária de uma rede nacional de farmácias.

As informações reunidas por este primeiro conjunto de emissões permite uma associação direta entre a localização dos imóveis que compõem cada uma das emissões e as áreas de maior valorização imobiliária da cidade de Ribeirão Preto, resultantes e produtoras de mudanças na estrutura desta cidade, sobretudo, pela velocidade e intensidade que a produção de novos empreendimentos habitacionais voltados aos segmentos de média e alta renda ganha a partir do início dos anos 2000 justamente nestas áreas (Abreu, 2014).

\section{Quadro 1 - Ribeirão Preto: descrição das emissões de CRI - 2006-2012 - Cibrasec}

\begin{tabular}{|l|l|l|l|l|}
\hline série & 52 & 105 & 106 até 113 & 187 \\
\hline ano da emissão & $08 / 08 / 2006$ & $27 / 02 / 2009$ & $31 / 03 / 2009$ & $03 / 02 / 2012$ \\
\hline cedente & $\begin{array}{l}\text { empresas de } \\
\text { construção } \\
\text { civil<?> }\end{array}$ & Bradesco & Bradesco & $\begin{array}{l}\text { empresa de } \\
\text { construção } \\
\text { civil<? }\end{array}$ \\
\hline coordenador líder & $\begin{array}{l}\text { empresas de } \\
\text { construção civil }\end{array}$ & $\begin{array}{l}\text { Banco Bradesco } \\
\text { BBI }\end{array}$ & $\begin{array}{l}\text { Banco Bradesco } \\
\text { BBI }\end{array}$ & Itaú BBA \\
\hline lastro total do pacote & $72 \mathrm{CCl}$ & $346 \mathrm{CCl}$ & $* *$ & $1 \mathrm{CCl}$ \\
\hline $\begin{array}{l}\mathrm{n}^{\circ} \text { de CCls com } \\
\text { imóveis localizados em } \\
\text { Ribeirão Preto }\end{array}$ & 30 & 4 & 6 & 1 \\
\hline $\begin{array}{l}\text { uso predominante dos } \\
\text { imóveis securitizados } \\
\text { em Ribeirão Preto }\end{array}$ & residencial & residencial & $\begin{array}{l}\text { residencial e } \\
\text { comercial }\end{array}$ & comercial \\
\hline
\end{tabular}

fonte: Termo de securitização de créditos imobiliários - séries 52, 105, 106, 107, 108, 109, 110, 111, 112, 113 e 187 (Cibrasec, 2006, 2009, 2012).

** Informação não disponível.

8 Essa área diz respeito à parte da fazenda Olhos d’Água, propriedade localizada no sul do município de Ribeirão Preto e que consiste em um dos eixos de valorização imobiliária do município atualmente (Abreu, 2014; Barcella, 2015). 
Trata-se de áreas em profunda transformação, em que as características arquitetônicas e urbanísticas não se reproduzem no conjunto da cidade, e demarcam a acentuação dos processos de diferenciação social e econômica na cidade, principalmente quando atreladas às dinâmicas dos preços do solo urbano que, tal como caracterizado por Abreu (2014) e Barcella $(2015,2017)$ vem amplificando o patamar das desigualdades entre os diferentes setores das cidades.

As áreas da cidade onde se localizam os imóveis que conferem lastro à emissão de papéis (CRI) abarcada por este sistema de financiamento e pelos créditos lastreados e disponíveis ao mercado com projeções de ganhos a investidores apresentam-se, no período em questão sobreposta aos eixos de maior transformação e dinamismo econômico para os agentes imobiliários. A posição destes empreendimentos ao sul contrasta com as demais áreas, sobretudo, aquelas dos quadrantes norte onde estão localizados grandes conjuntos habitacionais e, mais recentemente, os empreendimentos do Programa Minha Casa Minha Vida (Abreu, 2014; Barcella, 2015, 2017).

\section{Mapa 1 - Ribeirão Preto: imóveis lastreados em emissões de CRI - Cibra- sec-2006-2012}

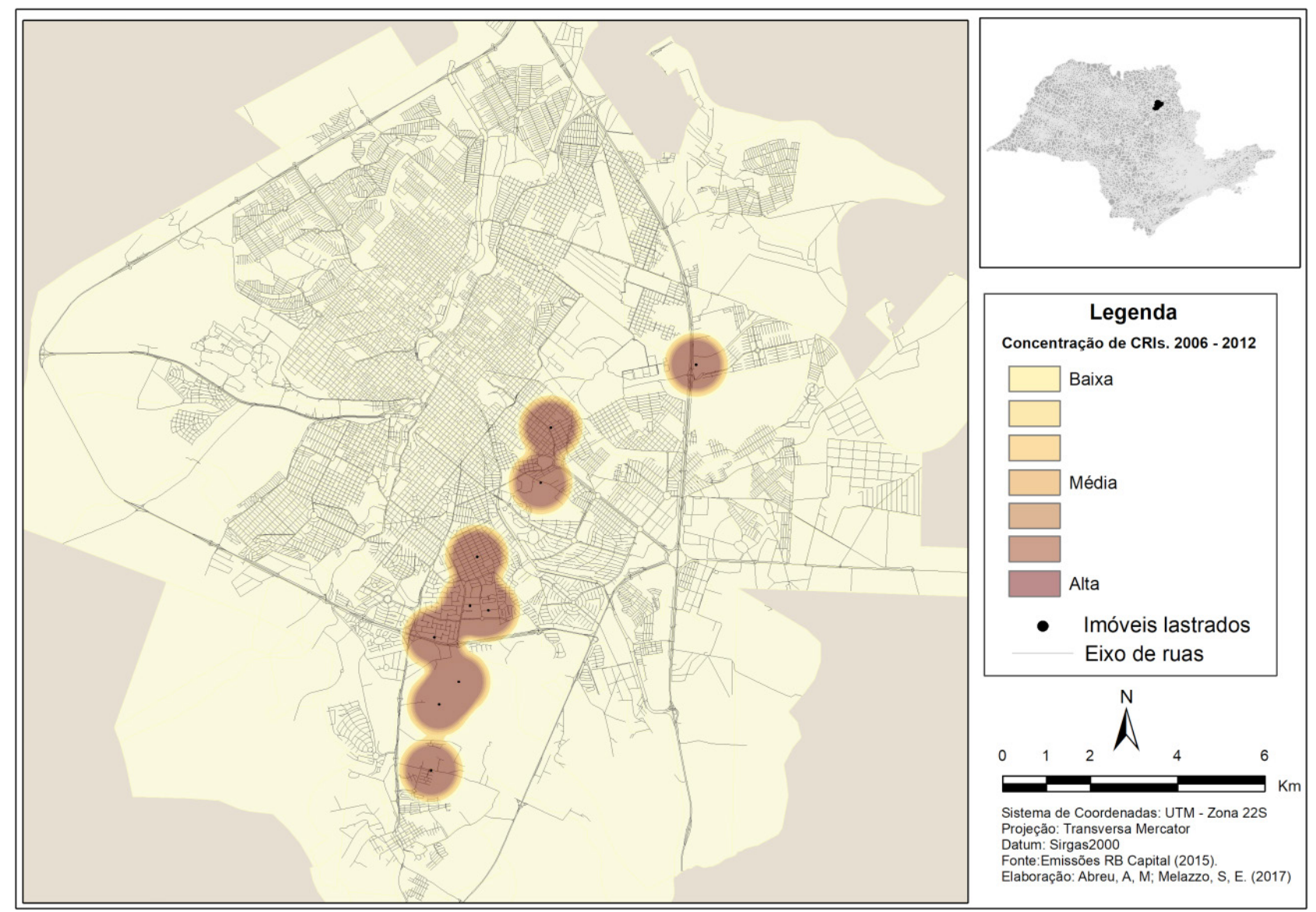

Como contraponto às emissões citadas, realizadas pela Cibrasec, são apresentadas a seguir aquelas realizadas pela RB Capital (Quadro 2) a partir de contratos de financiamento habitacional realizados pela Caixa Econômica Federal com Recursos oriundos do Sistema Brasileiro de Poupança e Empréstimo (SBBPE) e com investidor/comprador final definido, o fundo de investimentos do FGTS (FI-FGTS). 
Quadro 2 - Ribeirão Preto: descrição das emissões de CRI - 2014 - RB Capital

\begin{tabular}{|l|l|}
\hline séries & 110 e 111 \\
\hline ano da emissão & 2014 \\
\hline cedente & Caixa Econômica Federal \\
\hline coordenador líder & Caixa Econômica Federal \\
\hline número de unidades imobiliárias lastreadas no pacote & 5967 unidades \\
\hline número de unidades imobiliárias lastreadas em Ribeirão Preto & 531 unidades \\
\hline uso predominante dos imóveis securitizados em Ribeirão Preto & residencial \\
\hline
\end{tabular}

fonte: Termo de securitização de créditos imobiliários - séries 110 e 111 - RB CAPITAL ([s.d.]). organização: Os autores.

Organizado a partir de vários contratos, com abrangência nacional, o pacote da RB Capital do ano de 2014 (emissões de número 110 e 111) reúne 531 imóveis na cidade de Ribeirão Preto é assim radicalmente diferente das anteriores, seja em relação ao agente originador dos créditos, a CEF, o comprador último dos papéis (o FI-FGTS) e os tipos de imóveis que o compõem (de uso eminentemente residencial) e sua localização na cidade, o que pode ser observado no Mapa 2.

Mapa 2 - Ribeirão Preto: imóveis lastreados em emissões de CRI - RB Capital - 2014

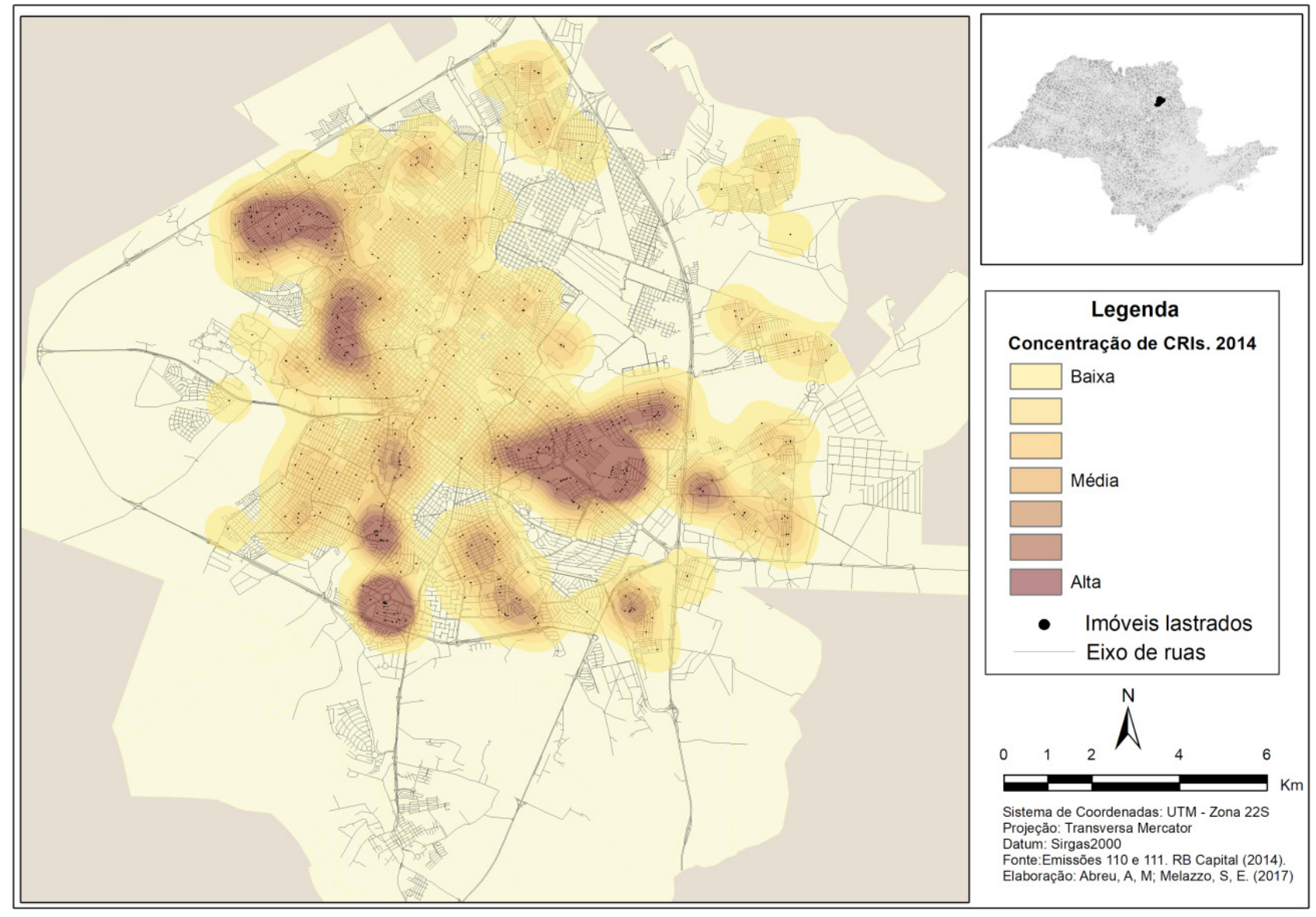


A localização dos endereços dos imóveis securitizados passa a apresentar um padrão bastante diferente das emissões anteriores. Enquanto no Mapa l a mancha dos imóveis restringe-se a uma faixa que se estende do centro em direção ao sul, no Mapa 2 observa-se ao mesmo tempo o surgimento de três grandes manchas de alta concentração (ao sul, a leste e na porção noroeste), mas também outras áreas com menor concentração. Assim, há uma disseminação do processo para imóveis localizados em diferentes e diferenciadas áreas em termos de tipos de edificação, padrão de ocupação e composição dos segmentos de renda que nelas residem.

Constata-se, assim, uma alteração não trivial quando se trata de emissões originadas a partir de financiamentos habitacionais, realizados pela CEF, a partir do SBPE e que se referem a imóveis residenciais, predominantemente, e que terão o Fundo de Investimentos do FGTS como principal comprador dos títulos originados pela securitização. A dispersão de tais operações pela cidade indicam claramente a expansão que tal engrenagem promove na captura de áreas, imóveis e segmentos de renda diferenciados para sua lógica.

\section{Considerações finais}

A partir da análise de dois conjuntos de emissões de CRI, na cidade de Ribeirão Preto, em momentos distintos e originados de diferentes tipos de produção imobiliária, é possível constatar a expansão não apenas quantitativa que paulatinamente passa a ser verificada dos instrumentos que, em nome da criação de estratégias que ampliem os volumes de recursos disponíveis para o financiamento imobiliário, passam a conectar a produção imobiliária aos mecanismos e engrenagens do mercado de capitais. Os papéis que passam a circular na esfera do financeiro abarcam cada vez mais conjuntos diversificados de imóveis em termos de uso e localização na cidade.

Ao focar a cidade de Ribeirão Preto o objetivo foi o de colocar em debate os processos que, para além das realidades metropolitanas, abarcam cada vez mais cidades de diferentes portes, com funções e papéis distintos no sistema urbano brasileiro. No mesmo sentido, reconhecer também sua disseminação para imóveis que não apenas de alto padrão ou alto valor unitário, de usos comerciais e de serviços, como edifícios de escritórios ou shopping centers, por exemplo, mas também para habitações coloca em debate a disseminação desta lógicas. Tais lógicas alteram e distanciam cada vez, para os agentes deste mercado em expansão, a habitação de seu valor de uso como abrigo e mesmo como propriedade individual para valores de troca que se realizam circulando como papeis nos circuitos financeiros. Por fim, chama-se a atenção para o papel não desprezível que cumpre cada vez mais intensamente nesta dinâmica a CEF e o FGTS, a primeira como originadora dos créditos de financiamento e o segundo como comprador final dos papéis. Por um lado, a CEF concedendo os financiamentos imobiliários criam a carteira potencial de créditos a serem securitizados e, de outro, o FGTS adquirindo tais papéis, garante a expansão da engrenagem, colocando a liquidez acumulada por este fundo de poupança forçada dos trabalhadores, a serviço das engrenagens financeiras.

Não se trata, fica claro, de discussão finalizada. Melhor seria tomar estas conclusões como pontos de partida para investigações que alcancem outras cidades, que aprofundem a análise a partir da identificação dos imóveis e seus usos em cada uma delas e que permita qualificar com mais profundidade, como traço característico da financeirização do imobiliário bra- 
sileiro, as íntimas articulações do mercado de capitais ao estado, ao fundo público e à poupança dos trabalhadores e seus desdobramentos contemporâneos sobre a produção e o consumo da terra urbana, da habitação e da cidade.

\section{Referências}

ANBIMA. ASSOCIAÇÃO BRASILEIRA DAS ENTIDADES DOS MERCADOS FINANCEIRO E DE CAPITAIS. Dados de emissão de CRI. Disponível em: http:// www.anbima.com.br/pt_br/informar/dados-de-emissao-de-cri.htm. Acesso em: 20 mar. 2018.

ABREU, M. A. O mercado imobiliário em Londrina e Ribeirão Preto: análise comparativa do processo de estruturação intraurbano. Relatório de qualificação (Mestrado) - Faculdade de Ciências e Tecnologia, Universidade Estadual Paulista, Presidente Prudente, 2014.

BARCELLA, B. L. S. O mercado fundiário em Ribeirão Preto-SP: processos e agentes, preços e localizações. Caminhos de Geografia, Uberlândia, v. 18, n. 62, 161-173, 2017.

BARCELLA, B. L. S. O mercado de terras urbanas e seu papel na produção e transformação do espaço urbano em cidades médias: os casos de Ribeirão Preto-SP e São Carlos-SP. Monografia (Conclusão do Curso em Geografia) - Faculdade de Ciências e Tecnologia, Universidade Estadual Paulista, Presidente Prudente, 2015.

BOTELHO, A. O urbano em fragmentos: a produção do espaço e da moradia pelas práticas do setor imobiliário. São Paulo: Annablume/Fapesp, 2007.

CIBRASEC. Companhia Brasileira de Securitização. Termo de securitização de créditos imobiliários: Cibrasec, 2006, 2009, 2012. São Paulo: [s.d.]. Disponível em: http://www. cibrasec.com.br/emissoes.asp. Acesso em: 14 mar. 2019.

CVM. COMISSÃO DE VALORES MOBILIÁRIOS. Distribuições Públicas de Certificados de Recebíveis Imobiliários: ICVM 400/03. Disponível em: http://webcache.googleusercontent.com/search?q=cache:Tew-aXAgiVIJ:www.cvm.gov.br/ menu/acesso_informacao/serieshistoricas/serieshistoricas/anexos/Distribuicoes-de-CRIs-Planilha-Individualizada. $x l s+\varepsilon c d=1 \varepsilon h l=p t-B R E c t=c l n k E g l=b r$. Acesso em: 20 mar. 2018.

FIX, M. Financeirização e transformações recentes no circuito imobiliário no Brasil. Tese (Doutorado em Economia) - Instituto de Economia, Universidade Estadual de Campinas, Campinas, SP, 2011.

FIX. M. São Paulo cidade global: fundamentos financeiros de uma miragem. São Paulo: Boitempo, 2007.

HAILA, A. The theory of land rent at the crossroads. Environment $\mathcal{E}$ Planning D: Society and Space, v. 9, p. 276-296, 1990. 
HAILA, A. Land as a financial asset: The theory of urban rent as a mirror of economic transformation. Antipode, v. 20, n. 2, p. 79-101, 1988.

HARVEY, D. Los límites del capitalismo y la teoría marxista. México, DF: Fondo de Cultura Económica, 1990.

MELAZZO, E. S. New elements for a research agenda on brazilian cities: the growth of real estate wealth and the widening of socio-spatial inequalities. Brazilian Geopraphical Journal, v. 7, p. 53-70, 2016.

MELAZZO, E. S. Interações, combinações e sinergias: produção do espaço urbano, dinâmicas imobiliárias e o programa Minha Casa Minha Vida em cidades médias brasileiras. In: BELLET, C.; MELAZZO, E. S.; SPOSITO, M. E. B.; LLOP, J. M. (Org.). Urbanização, produção e consumo em cidades médias/intermediárias. Presidente Prudente, SP: Unesp/Lleida, 2015.

PAULANI, L. M. Acumulação e rentismo: resgatando a teoria da renda de Marx para pensar o capitalismo contemporâneo. Revista de Economia Política, v. 36, n. 3, p. 514-535, jul./set. 2016.

PEREIRA, A. L. S. Intervenções em centros urbanos e conflitos distributivos: modelos regulatórios, circuitos de valorização e estratégias discursivas. Tese (Doutorado em Direito Econômico e Financeiro) - Faculdade de Direito, Universidade de São Paulo, São Paulo, 2015.

RB CAPITAL SECURITIZADORA. Termo de securitização de termos imobiliários: RB Capital, 2014. São Paulo: [s.d.]. Disponível em: http://www.rbcapitalsecuritizadora. com/emissoes/rb-capital-companhia-de-securitizacao/default.aspx?tipo=securitizacaoEid=109. Acesso em: 14 mar. 2019.

ROLNIK, R. A guerra dos lugares: a colonização da terra e da moradia na era das finanças. São Paulo: Boitempo, 2015.

ROYER, L. O. O FGTS e o mercado de títulos de base imobiliária: relações e tendências. Cadernos da Metrópole, São Paulo, v. 18, n. 35, p. 33-51, abr. 2016.

ROYER, L. O. Financeirização da política habitacional: limites e perspectivas. Tese (Doutorado em Habitat) - Faculdade de Arquitetura e Urbanismo, Universidade de São Paulo, São Paulo, 2009.

SANFELICI, D. La industria financiera y los fondos inmobiliarios en Brasil: lógicas de inversión y dinámicas territoriales. Economía, Sociedad y Territorio, v. 17, n. 54, p. 367-397, 2017.

SANFELICI, D. As escalas de acumulação na produção das cidades. In: CARLOS, A. F. A.; VOLOCHKO, D.; ALVAREZ, I. P. (Org.). A cidade como negócio. São Paulo. Contexto, 2015. p. 121-144.

SANFELICI, D. A metrópole sob o ritmo das finanças: implicações socioespaciais da expansão imobiliária no Brasil. Tese (Doutorado em Geografia Humana) - Faculdade de Filosofia, Letras e Ciências Humanas, Universidade de São Paulo, São Paulo, 2013. 
SHIMBO, L. Z. Habitação social, habitação de mercado: a confluência entre Estado, empresas construtoras e capital financeiro. Tese (Doutorado em Teoria e História da Arquitetura e Urbanismo) - Escola de Engenharia de São Carlos, Universidade de São Paulo, São Carlos, 2012.

UQBAR. Anuário: securitização e financiamento imobiliário. Rio de Janeiro, 2017.

UQBAR. Anuário: securitização e financiamento imobiliário. Rio de Janeiro, 2016.

UQBAR. Anuário: securitização e financiamento imobiliário. Rio de Janeiro, 2015.

UQBAR. Anuário: securitização e financiamento imobiliário. Rio de Janeiro, 2014.

UQBAR. Anuário: securitização e financiamento imobiliário. Rio de Janeiro, 2013.

UQBAR. Anuário: securitização e financiamento imobiliário. Rio de Janeiro, 2012.

VEDROSSI, A. O. A securitização de recebíveis imobiliários: uma alternativa de aporte de capitais para empreendimentos residenciais no Brasil. 2002. Dissertação (Mestrado em Engenharia de Construção Civil e Urbana) - Escola Politécnica, Universidade de São Paulo, São Paulo, 2002. 